\title{
Optimum design for reinforced concrete pavement by parallel finite element code
}

\author{
C. J. Martins ${ }^{1}$, R. R. Silva ${ }^{1}$, L. A. Martins ${ }^{2}$, E. V. Andrade ${ }^{1}$ \\ \& F. R. G. Padula ${ }^{1}$ \\ ${ }^{I}$ Department of Civil Engineering, CEFET/MG, Belo Horizonte, $M G$, \\ Brazil \\ ${ }^{2}$ Geological Survey from Brazil - CPRM Regional Bureau, \\ Belo Horizonte, MG, Brazil
}

\begin{abstract}
In this work, the structural behavior of reinforced hollow-core concrete slabs considered as industrial pavement will be displayed. The geometry of the plates was obtained by numerical modeling through computer algorithm based on the parallel Finite Element Method in, considering both the soil and concrete like elastoplastic materials. It will be shown that greater speed of execution and significant reduction in consumption of materials, and by this way, economy in the implementation of an industrial pavement through the design of a precast hollow-core concrete slab was obtained.
\end{abstract}

Keywords: PCP, constructive systems, non-linear finite element method, concrete pavement, hollow-core slabs, precasting concrete.

\section{Introduction}

Over the past decades, the industry focused on the construction of reinforced concrete floors is increasingly applying technological advances, resulting from extensive research on this topic. Such studies, involving the development and creation of new constructive techniques, development of concepts of structural design, allied to improvements made by standards aimed at this structural material has led to concrete pavements with high performance and durability, making these structures very competitive (Nasir et al. [1]).

Among the various technological developments for the construction of concrete railways, the adoption of precast concrete plates has made great 
progress over time. The use of reinforced concrete precast panels have as main advantages the quality and speed in implementing of the pavement, and allow reduction in the amount of material, equipment and labor deployed in site. Since the front work will have as main function simply placement of concrete slabs at correct place, while another very important jobs such as bar placement, concrete casting and cure, which stages a long time and significantly affect the quality of the structure, can be conducted on a more adequate place (Bruggeling and Huyghe [2], Wilde et al. [3]).

The performance of reinforced concrete pavement can be increased by adopting the concept of the pretension (Lin and Burns [4]). The introduction of compression prior to live load may be obtained by a rational way if it will be allied to the concept of precast. The pretension leads to panels with larger extensions and hence lower density of joints, prevention of premature cracks in the concrete and sections more economical (Corley et al. [5]).

Although the concept of prestressed concrete been widely applied in the construction industry in superstructure elements, for structural pavement few technical developments are reported. Hargett [6] reported the construction of a constructive system composed of precast concrete deck supported by a granular sub-base layer covered by sand. On the plates of concrete is applied layer of asphalt concrete. Also according Hargett [6] that system proved to be inefficient, since constructive difficulties caused by connection between the plates and premature cracks occurred in the asphalt layer. In Nishizawa et al. [7] is described a system consisting of paving slabs in precasted concrete of variable dimensions in plan, supported by mechanically stabilized sub-base, which showed satisfactory results. Kumakura et al. [8] proposed a system for load transfer between concrete slabs, composed of prestressed steel bars every 0.5 meters. Through this mechanism it was possible to obtain full transfer of loads between panels and precise union between them. Chisato et al. [9] reported research involving the study of the influence of the elements of transfer of load on pre-manufactured panels with varying dimensions. From extensive research on the performance of different systems pre-existing manufactured by the $80 \mathrm{~s}$, Cable et al. [10] developed new and important concepts involving the design and construction of prestressed concrete pavements. In Merritt et al. [11] presents a new constructive system composed of prestressed plates in situ. This system was initially tested in the laboratory and then in real conditions of use, giving excellent results (Merritt et al. [12]). Fort Miller [13] presents a system composed of prestressed plates aimed to apply in situations of heavy traffic (Lepree [14]) and when speed in the pavement execution was necessary. Chang et al. [15] present an extensive comparative study between the main techniques of precast pavement systems in reinforced concrete, analyzing the technical and economic features of these systems, both in the execution of repairs and in the development of new paved roads.

The techniques of pretension and precast developed for reinforced concrete structures made possible the implementation of structural elements of high quality and competitiveness. Aiming to make the structural components lighter and economical, the industry of precast slabs have adopted so-called prestressed 
hollow-core slabs as a rationale solution for implementation at floors and bridges. The slabs are formed by panels of cross section with constant height and longitudinal hollows, which reduce the consumption of material and weight of the structure. They are produced usually by adopting high-strength concrete (Class $\mathrm{C} 40$ or greater) and low slump, vibrating at high frequency equipment. For their constructive technique, they have reduced material consumption, high quality, competitive cost, reduced time to assembly and enable the adoption of large spans.

Although widely applied to structures of floors of high buildings and bridges (Bruggeling and Huyghe [2], Lin and Burns [4]), there aren't any research about the use of hollow-core precast concrete panels reported in technical literature about road pavement. This work aims to investigate the structural behavior for a structural system composed of hollow-core plates of prestressed and precast concrete pavement (PPCP), under moving load due traffic of off-road trucks about 652 tons. Numerical modeling conduced by a parallel Finite Element Method (FEM) code will be performed, with de goal to obtain responses of tension and displacement for the plates. Will be shown that this system offers excellent structural performance due heavy moving loads and allow implementation of large expanses of pavement in a quickly way with competitive cost.

\section{Structural concrete pavement}

\subsection{Concrete pavement}

During the design of a structure must be evaluated several ways, with the goal to determine the best solution for the project studied. The main factors influencing the decision are: availability of materials, equipment and of labor, safety, durability, economy and time. In order to choose the best option, you need the broad knowledge of the various existing technologies. Currently, the use of concrete on pavement of roads has become an excellent alternative to asphalt one. In the concrete pavement, the layer of rolling also works as structure, redistributing efforts and reducing the stress imposed on the sub-base, which usually is the only layer performed between the concrete slabs and sub-grade.

One of the main advantages of the surface of Portland cement concrete is durability. The concrete does not deteriorate with the action of rain, oil or fuels and not skew the point of forming the tracks of wheels. Thus, the ground can work hard over 20 years without interventions to undergo repairs or maintenance.

A well-prepared project contributes to the advantages presented by the concrete pavement. A conservative design may prevent the implementation of pavement by increasing their cost so much. An underestimate can cause structural problems and reduce the life of the pavement, forcing the execution of repairs and reinforcements that increase costs and cause inconvenience to users. Currently design of structures should incorporate concepts such as durability and performance. These concepts also apply to decks. A project must be done not 
only to ensure safety against fracture, but to meet the conditions of service for a certain period of time.

\subsection{Prestressed concrete pavement}

The concrete prestressed floor is used especially when there is heavy traffic. Its main application is the tracks and yards of airports and highway. According to Schmid [16], at prestressed concrete floor, the tensile strength of concrete is controlled by previously pretension that compresses the concrete, creating in him a reserve of tension that allows a reduction in the thickness of the plate. The plate is almost impermeable and with no cracks. The prestressed floor still has the advantage of the joints can be spaced up to 150 meters, but the execution is more sophisticated. The first pavement built with prestressed concrete in Europe and the United States, dating from 1945. In the 60s, this solution was used in the construction of industrial floors at Australia. As an example it may be cited the Brazilian International Airport of the Galeão, which was built with the technology of post-tension.

\subsection{Hollow-core concrete pavement}

The main advantages of precast systems are the reduced use of moulds, the diversity of types, the capacity to reach large spans and its economy. The hollow-core precast floors are used extensively for all types of construction, not only for precast concrete structures, but also in combination with other materials, for example steel structures, concrete cast on site, and so on. The choice of floor system varies for each type of construction and from country to country, depending on the transportation, facilities for assembly, market availability, constructive culture and so on.

Choosing the most appropriate elements for the floor is defined by a number of intervening factors: availability of the market, availability of transport, ease of assembly, cost of services. Hollow-core slabs systems are very suitable for large spans and high loads. Besides, being lighter than the massive slabs, it is possible to find mounting equipment in an easy way. In the same context, also the speed of implementation can play an important role. It is noteworthy that in countries where the cost of labor is low, there is less need to use industrial slab systems.

\section{Structural models}

For the determination of deformation and stress in any kind of structure, it required the use of physical and mathematical models representing the behavior of materials and the structure itself. Due to the complexity of the rheology of the materials and geometry of the structure, are adopted simplifications that allow the solution of the problem. To determine the efforts that direct or indirect loads are acting over concrete slabs supported by the ground, several theories were developed. The methods of scaling of concrete pavements are based on the equations developed by Westergaard [17], which published articles on determination of displacements, stresses and bending moments in thin elastic 
plates, supported on dense liquid. Other authors also proposed equations for the purpose of establishing values for the efforts in concrete slabs, especially the graphs of Pickett and Ray [18].

The concrete pavements has the characteristic of absorbing the moments under the load and transmit to the subgrade efforts of low intensity, not requiring therefore that bearing capacity of foundation be very large. Although not requiring great strength of soil, the roads can present problems when built on expansive soils, or on thick layers of soft clay. The occurrence of abrupt changes in the characteristics of subgrade can also impair the performance of the pavement. There are several ways to model the soil as a support layer for plate's structures. The most common are:

\subsection{Winkler's model}

The dense liquid model consists of a series of independent springs with constant $\mathrm{k}$. The tension at a point depends on the deformation at the point and is not affected by tensions in neighboring regions. The constant of proportionality $\mathrm{k}$ is known as the spring coefficient, Winkler's coefficient or subgrade modulus.

\subsection{Linear elastic model}

In linear elastic solid model, the soil is characterized by its elastic properties. While we do not exactly represent the behavior of the soil, the model is closer to reality compared to the Winkler's model. The model of linear elastic solid considered, in addition to normal reactions, shear efforts between the particles of the material. The displacement at a point is influenced by the tension at the point and the tension at points close together, this influence being inversely proportional to distance. The solid model of linear elastic analytical solution is more complex, issue that has lost importance due to advances of computer programs.

\subsection{Non-linear elastoplastic model}

Currently, available algorithms are developed through processes such as numerical finite elements, finite differences and boundary elements, which facilitates the application of the theory of nonlinear plasticity (Lemaitre and Chaboche [19]), for determination of structural response under several geometries and loading acting at different positions on the plates. Can be adopted various models for the soil and thickness of the plates can be variable.

\section{Industrial application}

A system for ore discharging consists of a floor over which off-road trucks operate. This floor has fifteen slabs of concrete structural placed over an existing concrete wall with sixteen meters high (Figure 1). These plates have dimensions of $12 \times 4$ meters in plan and are partially supported in the existing wall, resulting in a cantilever with 2.75 meters (Figure 2(a)). 
The ore discharging system consist a dense and operating industrial area were the execution of concrete works are not feasible, so the slabs that form the operating floor must be performed outside the final position and subsequently transported. In addition, on these floors is acting off-road trucks of 652 tons weight, which requires high capacity of panels.

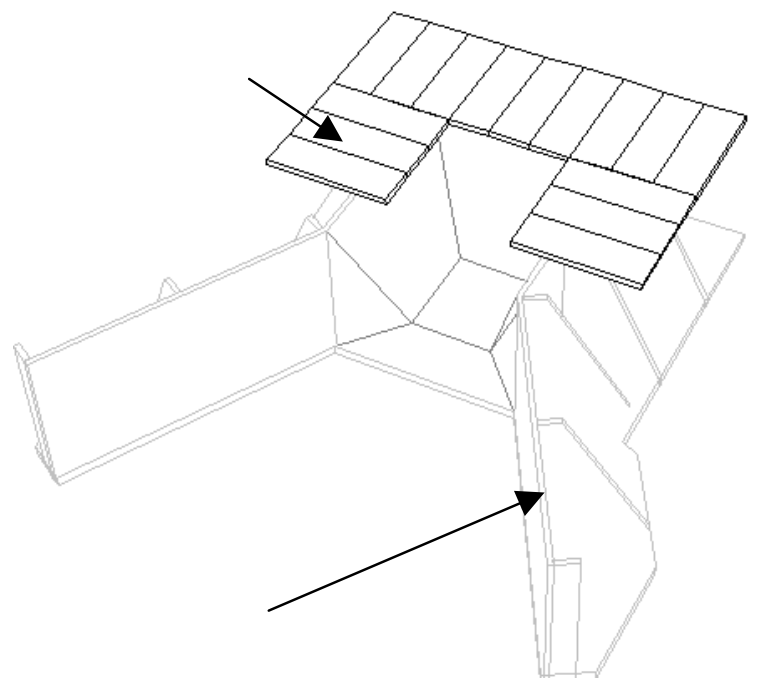

Figure 1: $\quad$ Ore discharging geometry.

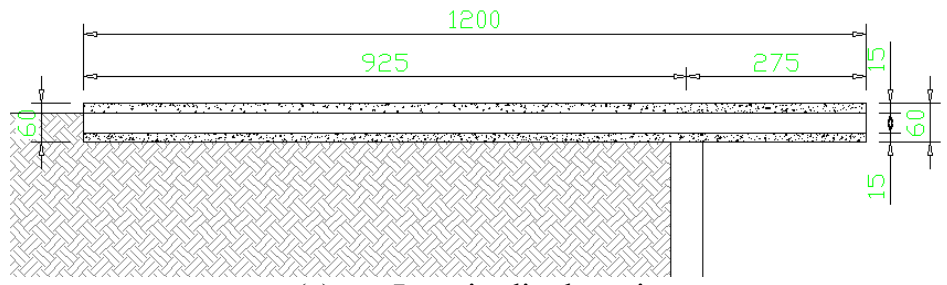

(a) Longitudinal section

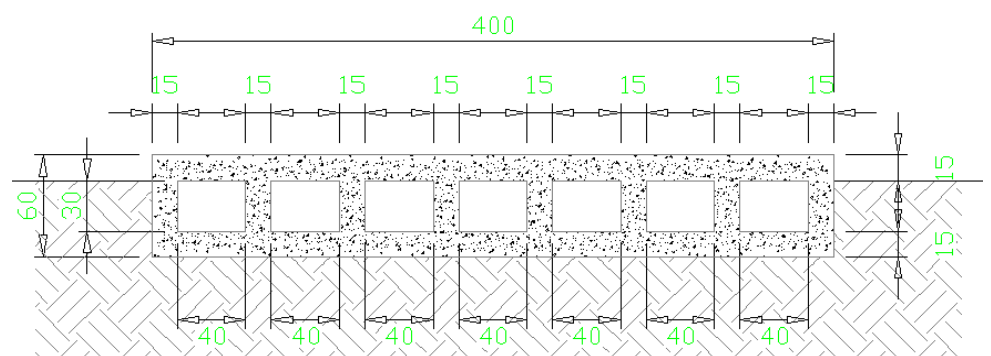

(b) Transverse section 1

Figure 2. 


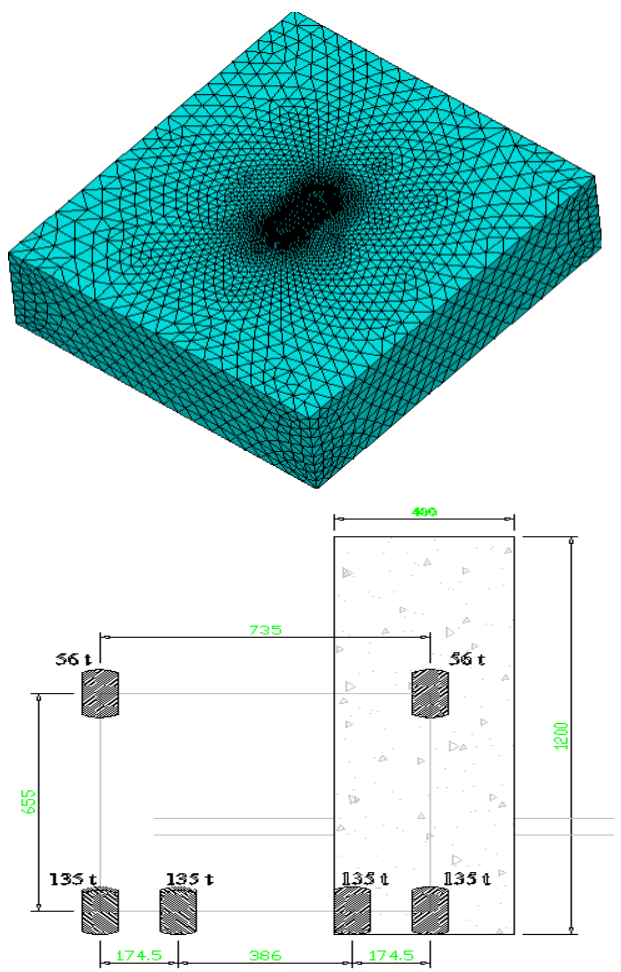

Figure 3: (a) Superior view of 3D mesh; (b) Traffic load model (centimeter, tons).

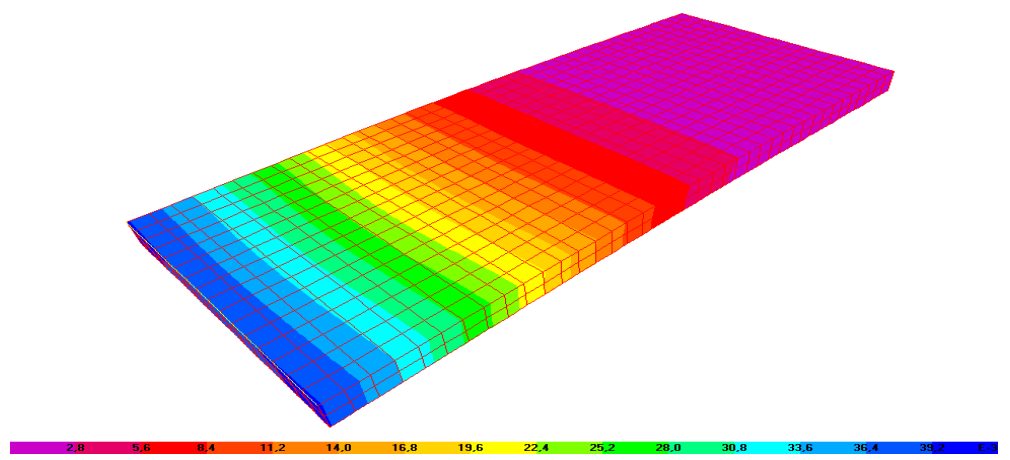

Figure 4: $\quad$ Vertical displacement (milímetro).

It was used to assemble precast panels hollow-core prestressed concrete since these elements combine high structural performance and lightness, allowing its transport and quick assembly. Figure 2(b) shows transversal section of the plates, made by structural concrete class $\mathrm{c} 40$, with $\mathrm{fck}=40 \mathrm{MPa}$, initial modulus of 
elasticity $\mathrm{Ec}=35 \mathrm{GPa}$ and Poisson coefficient $\mu=0,20$. The steel CA-50 used for the passive reinforcing of concrete structures has resistance characteristic fyk $=500 \mathrm{MPa}$ and modulus of elasticity Es $=196 \mathrm{GPa}$. For pretension was adopted CP-190RB12,7 steel, with tensile strength fy $=187,3 \mathrm{kN}$ and modulus of elasticity $\mathrm{Ea}=195 \mathrm{Gpa}$. The soil was formed of an initial layer of $16 \mathrm{~m}$ thick composed of compacted embankment $\left(\mathrm{Ee} 1=1 \mathrm{MPa}\right.$, Poisson $=0,4$, angle of friction $=15^{\circ}$, cohesion $=0,4 \mathrm{MPa}$ ) followed by a layer of compact sand thickness 6 meters (Ee2 $=6 \mathrm{MPa}$, Poisson $=0,45$, angle of friction $=30^{\circ}$ ). Under the compact sand, there are a layer in very hard sand. The level of the water table was not found. For the determination of reinforcement bar and concrete sections of the panels, Brazilian standard NBR-6118 [20] and NBR-7197 [21] was adopted, with concrete cover $\mathrm{d}=3 \mathrm{~cm}$ and cracks opening $\mathrm{wk}=0,2 \mathrm{~mm}$.

Figure 3(a) shows the mesh of the model considered in the soil simulation like a semi-infinite space. The model was discretized by approximately 0,6 million 3D Lagrangean elements, totaling 26 million degrees of freedom. The analyses were conducted by a parallel processing according domain decomposition concept, where the mesh was partitioning in four subdomain, which were processed in independent CPUs, adopting the Conjugated Gradient with Jacob Precondition (PCG) algorithm in the resolution of the resultant algebraic system. In Figure 3(b) it is shown the traffic load model considered. Figure 4 is presented the displacements envelopment obtained from the numerical analysis, considering the traffic load model operating in several critical positions on the panel. Figure 5 presents the resulting envelopment for the tensile stress at panel. From envelopment of tensions were determined both the sections of passive bar reinforcement $\left(0.27 \mathrm{~cm}^{2}\right)$ and pretension bar $(7$ bars CP-190RB12,7).

\section{Conclusion}

Techniques of prestress ally the concept of precast of structural elements in reinforced concrete was applied to industrial pavement with the purpose of reducing costs and increasing construction speed. As the constructive system was formed by hollow-core slab panels, although widely applied to structures of bridges and buildings, no application concerning paving has been reported in technical literature.

This paper presented a case study, in which precast panels formed by hollowcore prestressed panels were adopted as the rational solution for construction of industrial pavement where trucks with very high weight will operate. This structural solution in the industrial area with high traffic volume, presented themselves as the logical choice because it allowed the manufacture of boards outside the region of high-density operations.

Numerical modeling was performed by algorithm based on parallel Finite Element Method (FEM), resulting in responses of tension and displacement of the panels. From these responses, the design was conducted according to applicable Brazilian standards. It was shown that these plates allowed the construction of a pavement system with the purpose of receiving high loads of 
trucks, and thus absorbs very high efforts. Finally it was shown that this system offers excellent structural performance by moving loads and allows implementation of large expanses of pavement quickly and rational, may be better studied and possibly applied to highways.

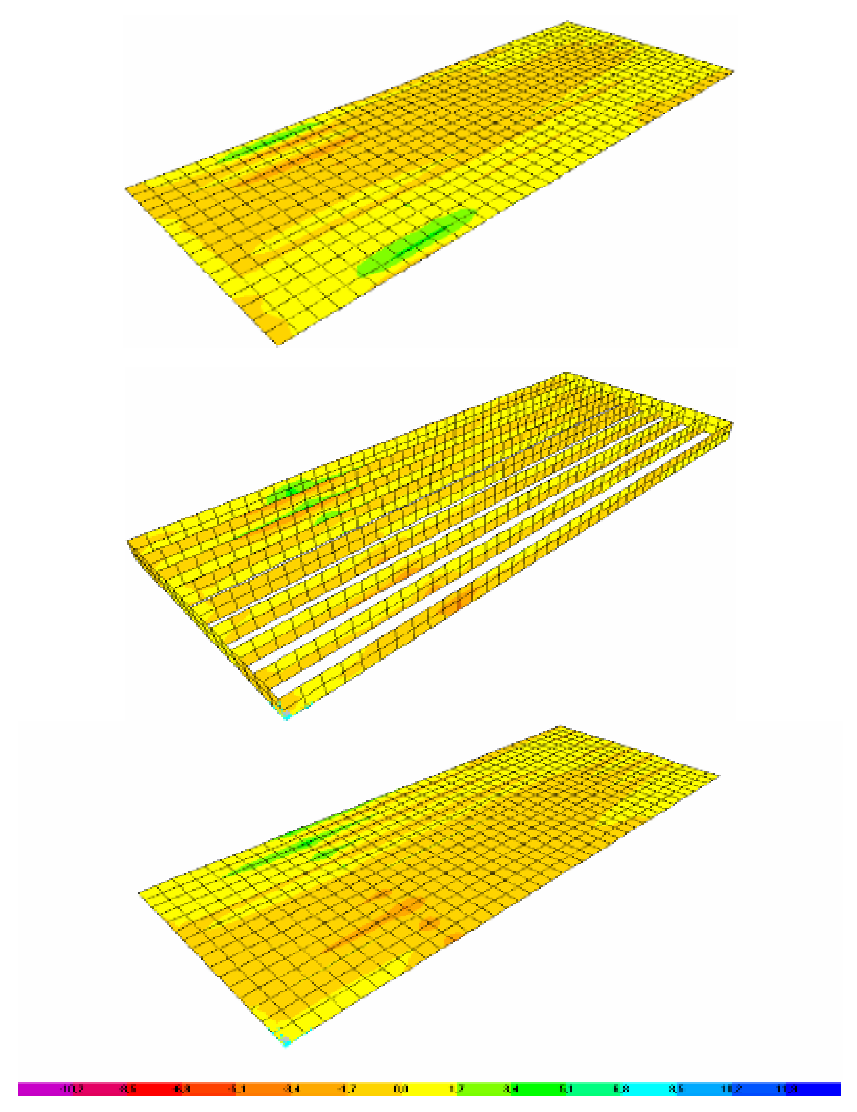

Figure 5: Tensile stress envelopment $-(\mathrm{kPa})$.

\section{Acknowledgement}

The authors acknowledge the financial support by FAPEMIG.

\section{References}

[1] Nasir G.G., Joseph S., Michael ID. Evaluation of Concrete Pavement Construction Scenarios Under Performance-Related Specifications, Transportation Research Record: Journal of the Transportation Research Board, vol. 1813, 2007. 
[2] Bruggeling A.S.G. and Huyghe G.F. Prefabrication with Concrete, A.A. Balkema Publishers, Rotterdam, Netherlands, 1991, 380 pp.

[3] Wilde W.J., Waalkes S. and Harrison R. Life Cycle Cost Analysis of Portland Cement Concrete Pavements, Research Report 1739-1, Center for Transportation Research, The University of Texas at Austin, September 1999, pp. 65-95.

[4] Lin T.Y. and Burns N.H. Design of Prestressed Concrete Structures, 3rd ed., John Wiley and Sons, Inc., 1981, pp. 1-30.

[5] Corley W.G., Colley B.E., Hanna A.N., Nussbaum P.J. and Russell H.G. Prestressed Concrete in Transportation Systems, PCI JOURNAL, V. 25, No. 3, May-June, 1980, pp. 14-31.

[6] Hargett E.R. Field Study of Performance and Cost of a Composite Pavement Consisting of Prestressed Concrete Panels Interconnected and Covered with Asphaltic Concrete, Highway Research Record Number 239, Highway Research Board, 1968, pp. 137-149.

[7] Nishizawa T., Noda E. and Fukuda T. Study on the Mechanical Behavior of Precast Concrete Pavements, International Symposium on Concrete Roads, Vienna, 1994, pp. 93-98.

[8] Kumakura M., Kondo S., Kai K., Abe Y. and Sato R. Development of a Prestressing Method for Joints of Precast Prestressed Concrete Pavement Slabs, International Symposium on Concrete Roads, Vienna, 1994, pp. 8388 .

[9] Chisato H., Ikeda T., Matsuno S. and Nishizawa T. Long Term Performance of Prestressed Concrete Pavements in Japan, Purdue Conference on Concrete, Indiana, 1997.

[10] Cable N.D., McCullough B.F. and Burns N.H. New Concepts in Prestressed Concrete Pavement, Research Report 401-2, Center for Transportation Research, The University of Texas at Austin, 1985.

[11] Merritt D.K., McCullough B.F. and Burns N.H. The Feasibility of Using Precast Concrete Panels to Expedite Highway Pavement Construction, Research Report No. 1517-1, Center for Transportation Research, The University of Texas at Austin, 2000.

[12] Merritt D.K., McCullough B.F. and Burns N.H. Precast prestressed concrete pavement pilot project near Georgetown, Texas, Paper No. 032726, TRB 2003 Annual Meeting, pp.5, 6.

[13] Fort Miller Co. Super-slab ${ }^{\circledR}$ really is a fast (and permanent) method of repair, Super-Slab Bulletin, vol. 1, issue 1, 2007.

[14] Lepree J. Taking a Tol, Precast Solutions, 2002, pp10 12.

[15] Chang, L., Chen, Y. and Lee, S. Using Precast Concrete Panels for Pavement Construction in Indiana, Indiana Department of Transportation State Office Building, 2004.

[16] Schmid, M.T. O pavimento rígido em concreto protendido. In: REIBRAC, 38., Ribeirão Preto, 1996. Anais, Ribeirão Preto, IBRACON. v. 1, p. 79-91.

[17] Westergaard H.M. Stresses in concrete runways of airports. In: annual meeting of hightway research board, Washington Proceedings, Washington, Hightway Research Board. p. 197-205, 1939. 
[18] Pickett G. and Ray G.K. Influence charts for concrete pavements. American Society of Civil Engineers, p. 49-73, 1951.

[19] Lemaitre, J. and Chaboche, J. L. Mechanics of solid materials. Cambridge University Press, 1994.

[20] NBR-6118, 2003. Projeto e execução de obras de concreto armado, $A B N T$.

[21] NBR-7197, 1989. Cálculo execução obras de concreto protendido, $A B N T$. 